\title{
A REAL-TIME GIS PLATFORM FOR HIGH SOUR GAS LEAKAGE SIMULATION, EVALUATION AND VISUALIZATION
}

\author{
M. Li ${ }^{\mathrm{a}, \mathrm{b} *}, \mathrm{H} . \mathrm{Liu}^{\mathrm{a}}, \mathrm{C} . \mathrm{Yang}^{\mathrm{b}}$ \\ ${ }^{a}$ Institute of Remote Sensing and Geography Information System, Peking University, Beijing, 100871- (mli, huil) @ pku.edu.cn \\ ${ }^{b}$ NSF Spatiotemporal Innovation Center and Department of Geography and GeoInformation Sciences, George Mason University,
} Fairfax, VA, USA; - (mli15, cyang3) @gmu.edu.cn

KEY WORDS: Real-time GIS, Emergency Response, CALPUFF, Hydrogen Sulphide, Gas Dispersion Simulation, Well Blow

\begin{abstract}
:
The development of high-sulfur gas fields, also known as sour gas field, is faced with a series of safety control and emergency management problems. The GIS-based emergency response system is placed high expectations under the consideration of high pressure, high content, complex terrain and highly density population in Sichuan Basin, southwest China. The most researches on high hydrogen sulphide gas dispersion simulation and evaluation are used for environmental impact assessment (EIA) or emergency preparedness planning. This paper introduces a real-time GIS platform for high-sulfur gas emergency response. Combining with real-time data from the leak detection systems and the meteorological monitoring stations, GIS platform provides the functions of simulating, evaluating and displaying of the different spatial-temporal toxic gas distribution patterns and evaluation results. This paper firstly proposes the architecture of Emergency Response/Management System, secondly explains EPA's Gaussian dispersion model CALPUFF simulation workflow under high complex terrain and real-time data, thirdly explains the emergency workflow and spatial analysis functions of computing the accident influencing areas, population and the optimal evacuation routes. Finally, a well blow scenarios is used for verify the system. The study shows that GIS platform which integrates the real-time data and CALPUFF models will be one of the essential operational platforms for high-sulfur gas fields emergency management.
\end{abstract}

\section{INTRODUCTION}

The high-sulfur gas production (content from $2 \%$ to $10 \%$ ) accounts 60 percentage of total natural gas output of China. The Luojiazhai and Gunziping gas fields, located in northeastern Sichuan province and Chongqing municipality with characteristics of ultra-deep, high pressure, high content, long pipeline and complex terrain, is the most important high-sulfur natural gas field in the country (Wu and Carroll, 2008). Therefore, developing high sour gas field is faced with a series of technical problems, which include safety control technology, standards and management system, work safety and emergency disposal. An emergency system is placed high expectations and several factors must be taken into account.

1) The gas field locates in the mountainous and hill areas. Once the terrain is basin and the residents settle in the low areas, it is very likely to accumulate the high content sulfur gas and do harm to person's health. The gas emergency emission model needs to considerate the influence of the terrain factor.

2) Low air temperature, heavy air humidity and weak wind speed is against to gas diffusion. Therefore, the real-time weather condition is very important for the gas dispersion simulation.

3) Once the gas leak happens, the preliminary emergency response is to dynamically simulate the toxic gas distribution, evaluate the harmful impact on local residents, setup the evacuation areas and find the optimal routes to the emergency muster points.

4) Located in mountain areas of northeast Sichuan province and Chongqing municipality, with complex terrains, weak infrastructure, and scattered population. Efficient notification and evacuation become especially important.

Over the last several years, emergency management has become more complicated. Large-scale emergencies and intelligent response seem to be more prevalent (ESRI, 2008). Geographic information system can provide the $2 \mathrm{D}$ and $3 \mathrm{D}$ platform for comprehensive emergency management. Traditional GIS technology provides the capability to map and analyze hazards of all types and visualize their potential impacts. When hazards are fused with critical infrastructure, population densities, and other community values, vulnerabilities can be observed, modelled, and better understood. Based on the potential impact of any particular hazard to critical values, priorities for mitigation can be established. Recent years, industrial controlling sensor, real-time GIS and atmospheric dispersion model provide the more accurate computation and analysis tools for emergency response.

Many research institutes and industry companies have did much work on these topics (Alhajraf et al., 2005; Liu et al., 2011; Chen et al., 2013; Jeong, 2014). For example, SAFER Real-Time application is the software developed by a US company, which provides rapid updates and visualizations based on actual weather and gas sensor data (Al-qurashi et al.,

* Corresponding author 
2004). It embeds an array of standard models covering fire and explosion, multi-component evaporation, building infiltration and exfiltration, tank and pipe, dispersion, complex terrain. The Chemical Accidents Response Information System (CARIS) was developed at the Center for Chemical Safety Management in South Korea (Kim et al., 2004). This system also content a set of Dispersion and Air Quality Modelling (DAQM), including SLAB (Atmospheric Dispersion Model for DenserThan-Air Gas), ALOHA (Areal Locations of Hazardous Atmospheres), VCE (Vapor Cloud Explosion) and so on. The operational modelling system, consisting of weather forecasting and dispersion models, can predict effectively the trajectory of chemical movements and assess the duration of chemical passage. In China, the Institute of Public Safety Research (IPSR) of Tsinghua University has conducted several national-level emergency response platforms, which provide the functions of maintaining channels of communication between the State Council and the related government departments. Based on ArcGIS platform, these systems show fundamental geographic information, population distribution, emergency resources, rescue teams and disaster simulation results on the digital map, run the a serial of spatial-temporal simulation models, predict the trend of disaster and display on the large screen of the control centres.

This paper proposes a GIS-based Emergency Response/Management System (ERMS) for high sour gas field, which provide data management of remote sensing image, terrain, road, population and housing, work safety and industrial control, emergency resource and so on. Once the gas leakage occurred, the system could dynamic simulate the gas emission with real-time meteorological and industrial leakage data, evaluate the serious casualties and economic losses, and outline the influenced areas, provide the effective and efficient notification and evacuation to the public, and help to make decision for emergency preparedness, emergency response and recovery.

\section{METHODOLOGY}

\subsection{Real-time GIS Platform for Emergency Response}

Real-time GIS refers to a GIS platform which can dynamically analyse sensor data and other live feeds, then puts it on interactive maps for real-time decision-making. It gives users the ability to connect to real-time data streams from a wide variety of sensors, perform continuous processing and analysis of those data streams, and send relevant information to users or other systems (Gong et al., 2014). According to this conception, ERMS system which connects with industrial gas leakage monitoring sensors and meteorological stations for toxic gas dispersion evaluation and emergency decision making can be taken as a typical example of real-time GIS application. We develop a 2D and 3D GIS platform based on a ServiceOriented Architecture (SOA), and build a flexibly integrated application system. This system tries to keep the separation principle in multi-tier distributed architecture for data storage, model, service and application, and can be sustainable expanded in order to meet the changing requirements of emergency management. Figure 1 depicts the architecture of ERMS system. The system includes four layers.

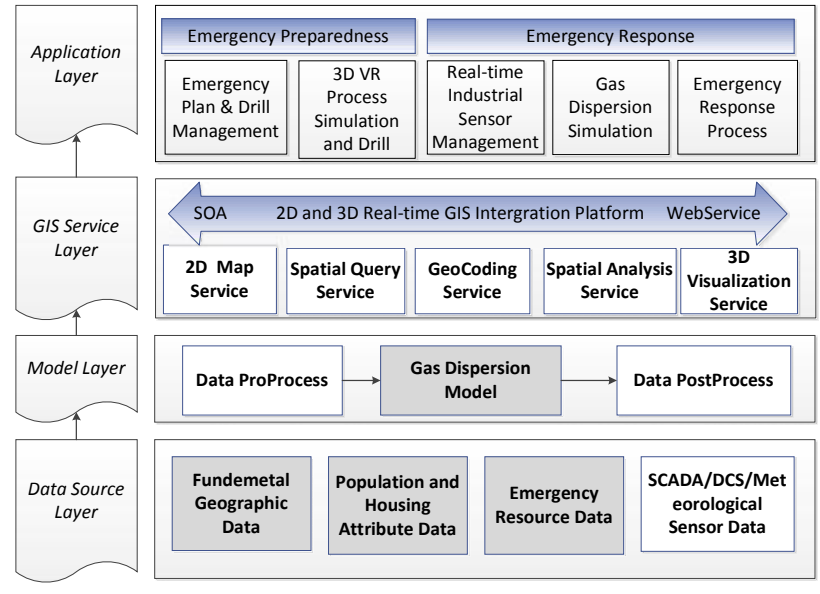

Figure 1. The architecture of Emergency Response/Management System

Data source layer: This layer provides the static database which stores and manages fundamental geographic data such as DLG, DEM, DOM, raster data, Geocode and 3D model. It also stores very detailed household surveying information such as telephone number of emergency contact, structure of household population, structure of house, the population of disable, mental illness and blind people. Furthermore, data source layer manage the thematic emergency resource data from contingency plans. Real-time sensor data from Distributed Control System (DCS) and Supervisor Control and Data Acquisition (SCADA) or third-party provider are input into the database from industrial network. The database source supports SQL Server, Oracle, IBM DB database, and solves the problems of the massive data organization, transaction processing, multi-user concurrency and other key database technology.

Model Layer: The system encapsulates the gas dispersion model as a service, which means the ERMS system just needs to prepare the dynamic data, feed them into the model interface and get the output without need to know model's detailed information. CALPUFF model combines real-time meteorological data with topographical data to calculate a detailed treatment of atmospheric dispersion that is threedimensional, terrain-influenced, and spatially and temporally varying. Moreover, model layer can extent gas dispersion models from one single model to a set of model or extent the single node computing to parallel computing.

GIS Service Layer: This layer provides the 2D and 3D integrated GIS service. The real-time GIS platform has the rich geographic resource and interface for secondary development, gives a full solution of geographic spatial information share such as WMS, WFS and TMS, provides 2D map service, spatial query service, geocoding service, spatial analysis service and $3 \mathrm{D}$ visualization service, and realizes the geographic information releasing, map service aggregation and application.

Application Layer: This layer realizes the functions of emergency preparedness and emergency response to meet the requirements of system, including submodules of emergency plan and drill, 3D virtual reality simulation and drill, industrial sensor data management, gas dispersion simulation, and emergency respond process. 


\subsection{Computer Network of Real-time GIS Platform for Emergency Response}

Figure 2 is simplified diagram of ERMS's network. A real-time historical database server, a database server, a gas dispersion server, a GIS server and a web service are used in this network. The gas dispersion server can be changed into server cluster in the future.

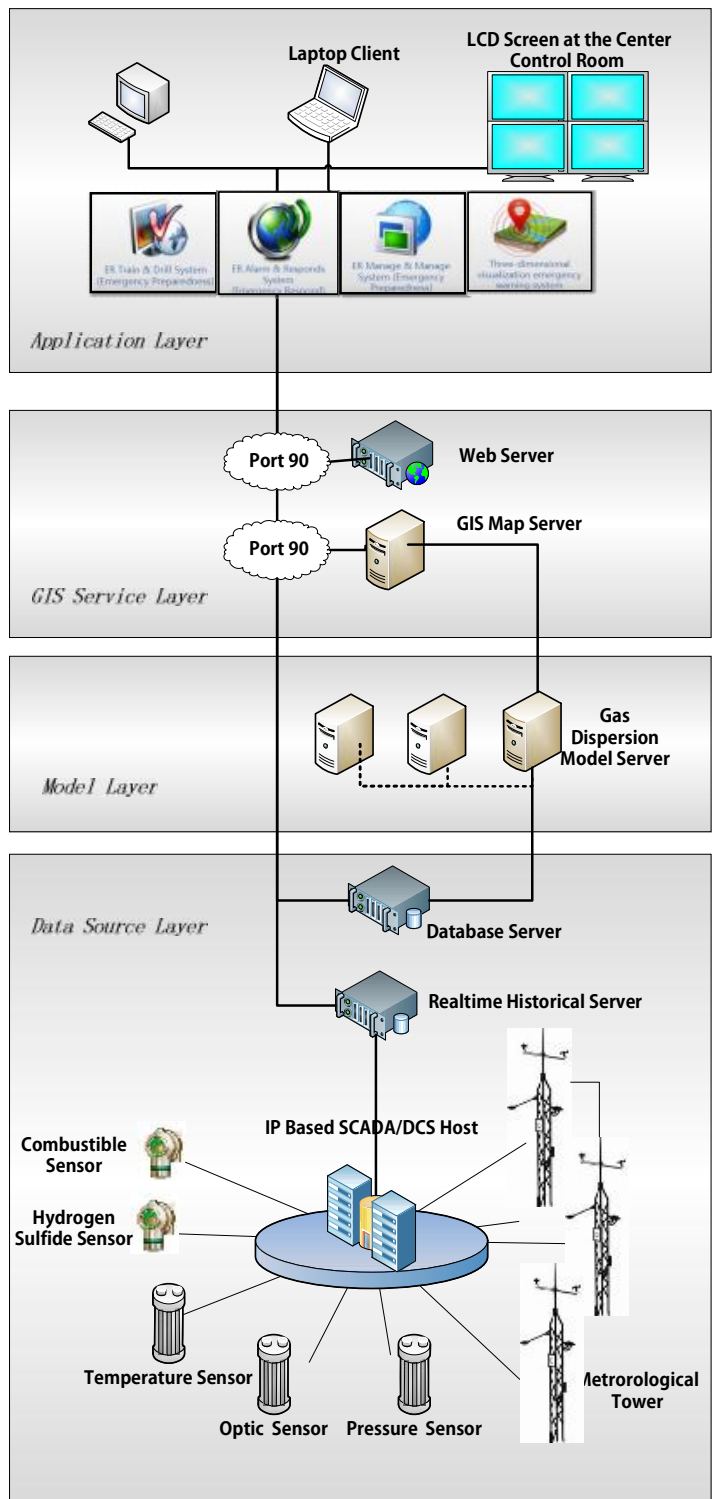

Figure 2. Emergency Response/Management System Computer Network

As for real-time sensor data, there are two different toxic gas detecting system to collect real-time data. Fire and Gas system, with the combustible gas detectors and the hydrogen sulfide toxic gas detectors, achieves the leakage detection and alarming of fires, combustible gas and toxic gas for the whole gas plant, well pad and gas gathering station. Pipeline Leak Detection System is a permanently-installed system which continuously monitors for leaks of pipeline from fiber optic temperature sensing, fiber optic acoustic sensor and negative pressure wave. Meteorological monitoring stations are installed at each gas gathering station, valve station, well pad, gas plant, and at multiple sensitive receptor locations. The real-time historical server collects these data from SCADA/DCS host and transfers to the ERMS SQL database. Real-Time gas dispersion model gets data from SQL database, runs the CALPUFF model and sends the result as a file to the map server during an emergency. CALPUFF model can be run in parallel computing environment in the future. The map server turns the file into raster image, overlays the result on the basic GIS map and display 2D and 3D visualization. The result can be accessed on the desktops, or large screen of the Center Control Room.

\subsection{The Workflow of Gas Dispersion Mode}

In the most case, SLAB, ALOHA and other denser-than-air gas models are chosen to embed with emergency response system. The reason is that the execution time is very short and suit for emergency emission. Another reason is the time step of these chemical and petroleum-chemical industries gas leak is in seconds or minutes, taken for granted the research area is a the flat terrain. The sour gas is the mixture of hydrogen sulphide and methane, lighter than air. SLAB or ALOHA is not suitable for sour gas dispersion. The non-denser-than-air gas dispersion models, such as AERMOD (Air Dispersion Modelling) and CALPUFF (California Puff Model), do take the 3D terrain into consideration, however they are usually used for environmental impact assessment (EIA) or emergency preparedness planning. That means the gas leak simulation is working for evaluation of the maximum likelihood of accident but no for emergency emission. What's more, data and simulations of non-denserthan-air gas dispersion models are made with a 1-hour time step commonly.

After the careful examination of different gas dispersion models, we choose CALPUFF6.4 model for ERMS system. CALPUFF V6.0/V6.4 allows times to be identified to the second or minute, and most importantly, the basic time step is no longer fixed at one hour so that it could be also characterized to the second. Each period is defined by both a start time and an end time, which means the execution time of each submodule is in seconds or in minutes in the process of three-dimensional wind field computation, dispersion process computation or postprocess computation. Another reason is CALPUFF can adjust wind field data according to terrain and meteorological principal to produce the gridded $3 \mathrm{D}$ object wind field, to embody the complex terrain affection.

CALPUFF model is one of the air quality models adopted by the United States Environmental Protection Agency (EPA). It is an advanced, integrated non-steady-state Lagrangian puff modelling system, for simulating the effects of time and space varying meteorological conditions on pollutant transport, transformation, and removal (Scire, 2011). The modelling system consists of three components and a set of preprocessing and postprocessing programs. CALMET, a meteorological modelling package with both diagnostic and prognostic wind field generators; CALPUFF, a Gaussian puff dispersion model with chemical removal, wet and dry deposition, complex terrain algorithms, building downwash, plume fumigation, and other effects; CALPOST and other postprocessing programs for the output fields of meteorological data, concentrations and deposition fluxes.

Figure 3 depicts the schematic diagram of the main components and the data flow used in calculating gas dispersion model. During a gas leakage response, secondly surface meteorological data are automatically acquired from SCADA system, including wind speed, wind direction, precipitation, temperature and humidity. In addition to the above parameters, CALMET 
parameter also need upper air data, elevation, land use and geophysical data such as surface roughness, length, albedo, Bowen ratio, soil heat flux parameter, and vegetation leaf area index. Once the wind field grid is set, CALMET outputs gridded meteorological data fields as CALMET.DAT. CALPUFF needs the three-dimensional meteorological fields developed by the CALMET model and emission source data from SCADA system, including emission source coordinate, height, diameter, emission rate, and set momentum flux factor, building data for sources subject to building downwash. Once the computation grid was set, CALPUFF would output CONC.DAT file which contain concentrations of simulated gas. CALPOST reads the concentration data from an unformatted data file CONC.DAT, and generates a file that concentrations needed to assess visibility. 2D file is time series 2D gridded concentration data in seconds. 3D file is time series 3D gridded data in seconds.

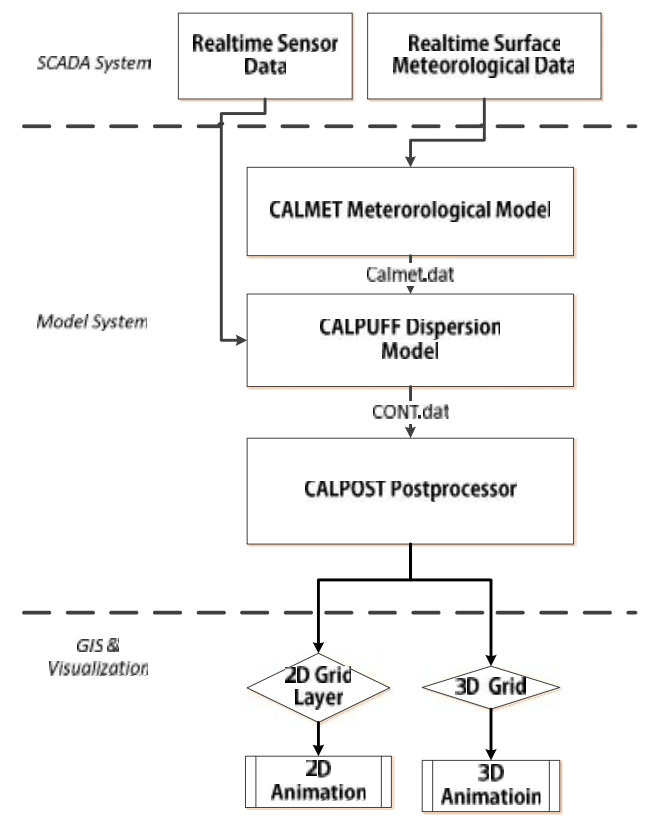

Figure 3. Schematic diagram of the main components and the data flow used in calculating gas dispersion model

\subsection{The Workflow and Key Problems of GIS Analysis of ERMS}

Emergency response grade of hydrogen sulphide leak in the contingency plan is determined by the level of severity of the specific incident. These are classified into Level I, II, III, and IV shown as Table 1. There are no direct link between emergency response grade and dose of hydrogen sulphide. Commonly above exposure $7.6 \mathrm{mg} / \mathrm{m}^{3}$ (5 ppm) need to evacuate.

According to the contingency plan, a recommended incident process of identification, notification, activation and evacuation has been developed. The most difficult part for emergency response is preliminary accident identification. The on-site staff should ensure the appropriate level of response is resourced on incidents by appropriate personnel and in a timely fashion. Figure 4 is simplified diagram of incident emergency response process.

\begin{tabular}{|c|l|}
\hline Level & \multicolumn{1}{|c|}{ Description } \\
\hline I & $\begin{array}{l}\text { The minor or simple incidents affecting a small area or } \\
\text { limited to a single unit, and has limited impacts to } \\
\text { personnel safety, environment, and affected facility or } \\
\text { operation. }\end{array}$ \\
\hline II & $\begin{array}{l}\text { The moderate or complex incidents with broad } \\
\text { impacts and requiring shutdown of a portion of the } \\
\text { affected facility or operation, and could result in } \\
\text { mustering or evacuation of operations. This type of } \\
\text { incident may involve natural disasters leading to fires, } \\
\text { spills of hazardous materials, gas release remaining on } \\
\text { the facility, and injuries resulting from event. }\end{array}$ \\
\hline III & $\begin{array}{l}\text { The major, complex, or compound incidents with } \\
\text { broader impact and requiring shutdown of all } \\
\text { operations of the affected facility or operation and } \\
\text { effect local communities. }\end{array}$ \\
\hline IV & $\begin{array}{l}\text { The catastrophic incidents with the complete } \\
\text { shutdown of the entire project and significant wide } \\
\text { spread regional effect. This type of incident may } \\
\text { involve natural disasters leading to major fires, large } \\
\text { spills of hazardous materials, significant gas release } \\
\text { reaching outside the exclusion zone, multiple injuries } \\
\text { and/or multiple fatalities resulting from event. }\end{array}$ \\
\hline
\end{tabular}

Table 1. Incident response levels of emergency response

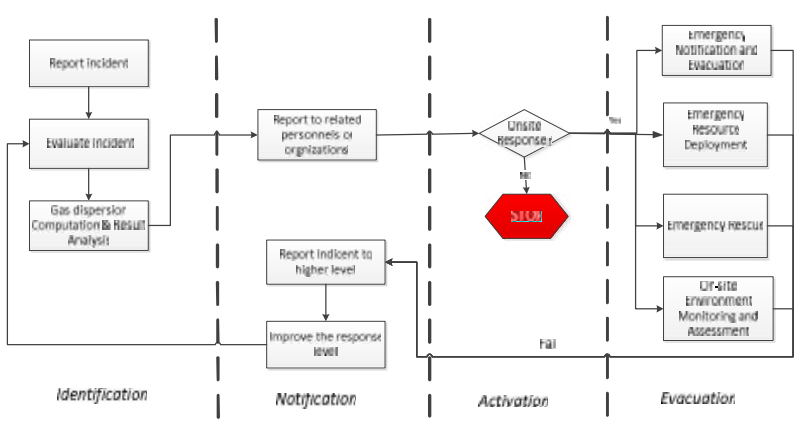

Figure 4. Simplified diagram of incident emergency response process

Once an incident were identified, the first action would be to make spatial-temporal analysis on the ERMS platform, which means to automatically run real-time gas dispersion model and manually outline evacuation regions and assembling regions. ERMS also makes network analysis to find the shortest path and time from evacuation points to the muster points and the shortest path and time consumption from emergency resource and emergency team to the incident spot. According to the incident grade, the staff notifies the incident to related organizations and activates the rescue process, the emergency notification and evacuation are carried on, the emergency resources are deployed, emergency teams are assigned with different tasks, such as on-site searching and rescuing, emergency repairing, on-site environment monitoring and assessing of air, water, soil, dangerous waste material, and resource. Once the emergency teams failed to rescue or the incident were expanding, the level of response should be 
improved into a higher level and the emergency response plan should be adjusted, the emergency rescue range should be enlarged.

\section{EXAMPLE RELEASE SCENARIOS AND DISCCUSSION}

\subsection{Scenario}

The research area is Luojiazhai and Gunziping gas fields, located in northeastern Sichuan province and Chongqing municipality. In the past decades, these gas fields have experienced a number of serious accidents ( $\mathrm{Li}$ et al., 2009). On 23 Dec. 2003, an accident of gas blowout occurred at the Luojiazhai No. $16 \mathrm{H}$ gas well. 243 people were killed, more than 4000 people were injured, more than 60 thousand people were evacuated and more than 93 thousand people suffered the disaster. A new gas project named Chuandongbei Gas Project redeveloped these gas fields in recent years, built 60 kilometre pipelines, 4 wells, 2 gathering stations, 11 valves, 1 purification plant and 1 sulfur plant.

Based on new project data, we simulate a sour gas well blowout in Kaixian County in our ERMS system for 12 hours (December 23, 2003, 22:00:00 to December 24, 2003, 10:00:00). According to the EPA's technical guidelines, the simulation area should not be smaller than $5 \mathrm{~km}$ from the emission point. As far as the research area is medial shallow incised mountainous region, the terrain height differences are about 500 - 1000 meters. The basic coordinate grid for CALPUFF/CALMET consisted of 50 grid cells along the $\mathrm{x}$-axis (east-west), 50 grid cells along the y-axis (north-south), and 10 grid cells along z-aix, spaced $1 \mathrm{~km}$ apart. The 10 vertical layers incorporated into the CALMET processing had heights of $20 \mathrm{~m}$, $40 \mathrm{~m}, 80 \mathrm{~m}, 160 \mathrm{~m}, 320 \mathrm{~m}, 640 \mathrm{~m}, 1200 \mathrm{~m}, 2200 \mathrm{~m}, 3000 \mathrm{~m}$ and $4000 \mathrm{~m}$. The meteorological, computational, and sampling grids are the same domain.

The average methane content in natural gas is about $82.14 \%$, average $\mathrm{H}_{2} \mathrm{~S}$ content $9.02 \%$. Mesoscale meteorological data (MM5) and observation, 1-km Global Land Cover Characterization (GLCC) data and 90-meter Shuttle Radar Topography Mission (SRTM) data were used to develop the wind field in CALMET. The gas leak source is granted as single isolated point source, with coordinate of emission centre is $(237.321 \mathrm{E}, 474.793 \mathrm{~N})$ of UTM projection. Stack height is 1 meters. Emission diameter is about 1 meter. Emission Rate is constant $6076.39 \mathrm{~g} / \mathrm{s}$. Exit velocity is $40 \mathrm{~m} / \mathrm{s}$ (Yang et al., 2006). The relative humidity was $94-99 \%$, the atmospheric condition was almost static (average wind speed equalled $0.13 \mathrm{~m} / \mathrm{s}$, and maximum wind speed equalled $0.7 \mathrm{~m} / \mathrm{s}$ ). The atmospheric stability is D-or E-degree. The final output of the CALPOST consisted of every 10 minutes $\mathrm{H}_{2} \mathrm{~S}$ exposure. Figure 5 demonstrates the location of gas well, villages and towns nearby on the remote sensing image.

We collect the several criterion on health effects of hydrogen sulphide, and choose the lethal concentration as 1008.55 $\mathrm{mg} / \mathrm{m}^{3}(700 \mathrm{ppm})$, half lethal concentration as $720.49 \mathrm{mg} / \mathrm{m}^{3}$ (500 ppm), exposure time is $30 \mathrm{~min}$, injury threshold as 150 $\mathrm{mg} / \mathrm{m}^{3}$ (100 ppm) and effect threshold as $15 \mathrm{mg} / \mathrm{m}^{3}$ (10 ppm).

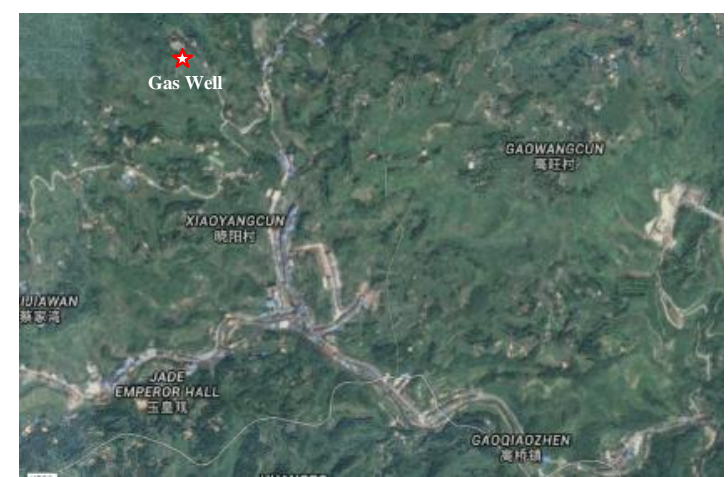

Figure 5. The location of gas well, villages and towns nearby (GOOGLE)

\subsection{Simulation Results}

Figure 6 demonstrates the concentration distribution map of the first $30 \mathrm{~min}, 1$ hour and 2 hour.

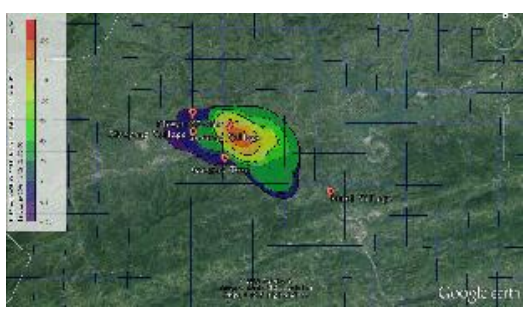

(a) $30 \mathrm{~min}$

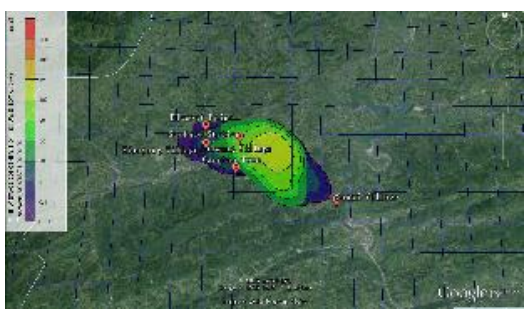

(b) 1 hour

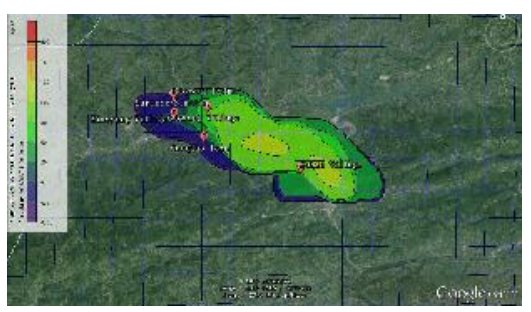

(c) 2 hour

Figure 6. Toxic gas concentration distribution map

From our simulation we can find in the first 30 minutes, the gas appears an oval zone with $80-180 \mathrm{mg} / \mathrm{m}^{3}(52.6-118.3 \mathrm{ppm})$ concentration, and cover the most area of the Xiaoyang village, Gaowang village and Gaoqiao town. In one hour simulation result, the toxic gas flew southeast along the village due to the effect of weak southeast wind and terrain with $60-120 \mathrm{mg} / \mathrm{m}^{3}$ (39.4-78.9ppm). In two hour simulation result, the toxic gas reached Sanxi Village with the a $60-80 \mathrm{mg} / \mathrm{m}^{3}(39.4-52.6 \mathrm{ppm})$ concentration.

The CALPUFF calculation results were largely in line with the fact. According to the reports and related research, the death 
mainly occurred in the area which is $300-500 \mathrm{~m}$ away from the well head with the longest distance of $1200 \mathrm{~m}$ in Xiaoyang Village, Gaowang Village and Gaoqiao Town. Due to data limitation, we cannot get the accurate monitoring data before the well was closing. After 7 hours later, the concentration of hydrongon sulphur was $11.4-32.2 \mathrm{mg} / \mathrm{m} 3 \quad(7.5-21.4 \mathrm{ppm})$ in Sanxi Village and Zhengba Town of Kaixian county.

Figure 7 depicts the 2D gas dispersion animation and Figure 8 depicts 3D gas dispersion animation of the ERMS system. Once the simulation button is clicked, the model will run and output the gas dispersion animation. The very detailed household surveying information such as telephone number of emergency contact, structure of household population, structure of house, the population of disable, mental illness and blind people will be displayed on the map. The system will export these data as XLS file.

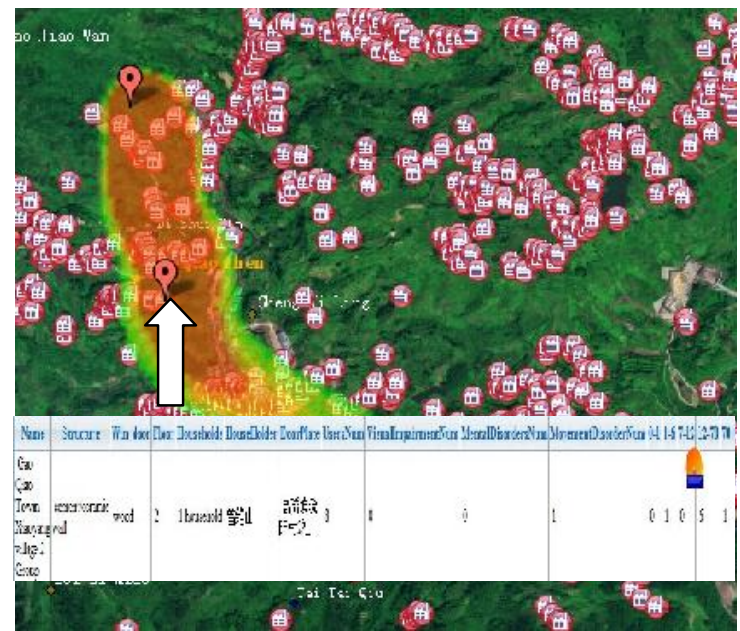

Figure 7. 2D gas dispersion animation on WebGIS

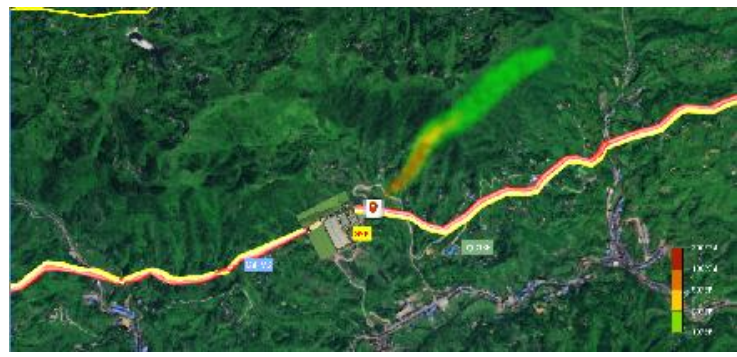

Figure 8. 3D gas dispersion animation on WebGIS

\subsection{Discussions}

The system demonstrates that the proposed method is feasible in assisting for the emergency response. Compare to the other ERMS system, there are several gaps to be filled by the our ERMS system development

1) We embed CALPUFF 6.0 or upper version into realtime GIS platform for simulating hydrogen sulphide gas dispersion. Compare with the other gas dispersion model, this model takes the complex terrain as consideration and the computation of basic time step is second level. This can meet the requirements of the natural gas project emergency response.

2) We can make quick emergency decision with GIS spatial analysis. CALPUFF model provides second-level simulation for emergency management purposes and outputs results in several minutes. In our example, it takes 2-4 minute to calculate the output.

3) 3D GIS can also provide an easier way to make community preparedness activities, training, exercises and advocacy. Traditionally these components are handled in very resourceheavy ways. The traditional emergency response could not make a real-time analysis and just response according to the pre-arranged planning. Now the GIS platform manages the basic information, including remote sensing data, village, house, residents, roads, population, emergency sensitive data, social and economic data and so on. Moreover, GIS can provide the dynamic statistical diagrams, tablets and various evacuation plans considering the gas dispersion results.

However, there has some limitations discussed in detail below.

1) Time consumption is in conflict with good accuracy when CALPUFF modelling computing. Finer terrain grid will cause the lower speed whereas lower grid will affect the model accuracy. However, this paper has not even started talking about this problem yet. It is very important to develop parallel CALPUFF dispersion modelling platforms and speed up the model computation task.

2) Furthermore, we also need to validate and improve model accuracy comparing with other research or tracer experiments.

3) GIS plays a very important role to provide data management, spatial analysis, and route analysis for emergency decision making. The updating function is of great importance during GIS project. Updating implies the resurvey and processing of new information. The emergency resources are dynamic changing. The routine maintenance of the Emergency Response/Management System is very important.

\section{CONCLUSIONS}

This paper proposes a high sour gas field emergency response system based on real-time GIS, mainly explains about architecture of GIS Platform, work flow of gas dispersion model and emergency response. A gas well blowout accident scenario is used to verify the real-time gas dispersion model and emergency response workflow. The study show that GIS platform which integrates the real-time data and CALPUFF models will be one of the essential operational platforms for high-sulfur gas fields emergency management, rapid response and emergency rescues.

\section{REFERENCES}

Alhajraf, S., Al-Awadhi, L., Al-Fadala, S., Al-Khubaizi, A., Khan, A.R., Baby, S., 2005. Real-time response system for the prediction of the atmospheric transport of hazardous materials. Journal of Loss Prevention in the Process Industries, 18, pp. $520-525$.

Al-qurashi, F., 2004. New vision of emergency response planning. Process Safety Progress, 23(1), pp.56-61.

Chen. W, Chen, S., Du, E., Wang. Y., 2011. Design and Development of Emergency Monitoring System to Sudden Air Pollution Accidents. Journal of Geo-information Science, 13(1), pp.65-72. 
Gong, J., Geng, J., and Chen, Z., 2015. Real-time GIS data model and sensor web service platform for environmental data management. International Journal of Health Geographics, 14:2.

Jeong, S., 2014. Developing Dispersion System with Detecting Autonomic Leak Location. Advanced Science and Technology Letters, 63 (NGCIT 2014), pp.248-253

Kim, C.-H., Park, J.-H., Park, C.-J., Na, J.-G., 2004. Operational Atmospheric Modeling System CARIS for Effective Emergency Response Associated with Hazardous Chemical Releases in Korea. Environ Manage, 33(3), pp.34554.

Li, J., Bin, Z., Yang, W., Mao, L., 2009. The unfolding of '12.23' Kaixian blowout accident in China. Safety Science, 47(8), pp.1107-1117.

Liu, F., Wang, X., Qian, Y., Kong, S., and Zheng, M., 2011. Emergency Rescue Decision Assistant System Based on GIS for Natural Gas Pipeline. In: International Conference on Pipelines and Trenchless Technology: Sustainable Solutions For Water, Sewer, Gas, And Oil Pipelines, Beijing, China, 26-29 October, pp. 304-314.

Scire, J., Strimaitis, D., Yamartino, R. 2011. CALPUFF Version 6 User Instructions. The Atmospheric Studies Group at TRC Solutions, pp:1-7.

Wu, Y and Carroll, J.J., 2008. A Review of Recent Natural Gas Discoveries in China. In: Sour Oil \& Gas Advanced Technology (SOGAT) Conference, Abu Dhabi, U.A.E., April 27-May 1, pp. 113-129.

Yang, D., Chen, G., and Zhang, R., 2006. Estimated public health exposure to $\mathrm{H} 2 \mathrm{~S}$ emissions from a Sour gas well blowout in Kaixian County, China. Aerosol Air Qual Res, 6(4), pp.430443.

ESRI® White Paper, 2008. Geographic Information Systems Providing the Platform for Comprehensive Emergency Management. https://www.esri.com/library/whitepapers/pdfs/gis-platform-emergency-management.pdf 